\title{
Numerical simulation and observations of very severe cyclone generated surface wave fields in the north Indian Ocean
}

\author{
P Sirisha $^{1}$, P G Remya ${ }^{1}$, T M Balakrishnan NAir ${ }^{1, *}$ and B Venkateswara RaO ${ }^{2}$ \\ ${ }^{1}$ Indian National Centre for Ocean Information Services, Pragathi Nagar, Hyderabad 500 090, India. \\ ${ }^{2}$ Centre for Water Resources, Jawaharlal Nehru Technological University, Hyderabad 500 085, India. \\ ${ }^{*}$ Corresponding author. e-mail: bala@incois.gov.in
}

Accurate wave forecast is most needed during tropical cyclones as it has adverse effects on the entire marine activities. The present work evaluates the performance of a wave forecasting system under very severe cyclonic conditions for the Indian Ocean. The wave model results are validated separately for the deep water and shallow water using in-situ observations. Satellite altimeter observations are also utilized for validation purpose. The results show that the model performance is accurate (SI $<26 \%$ and correlation $>0.9$ ) and consistent during very severe cyclones (categories 4 and 5 ). The power of the cyclone waves which hit in the eastern Indian coastal region is also analysed and it reveals that the coastal region which lies on the right side of the cyclone track receives high amount wave energy throughout the cyclone period. The study also says that the abnormal waves mostly present on the right side of the track.

\section{Introduction}

The rapidly varying intense winds associated with tropical cyclone (TC) can produce high and complex wave fields which propagate thousands of kilometers away from the center of the storm. These high waves pose major devastation to property and cause loss of life in the coastal areas especially during landfall. The impacts of TC depend on the amount of wave energy reaching the shore which is greatest during TC landfalls (Peter et al. 2008).

Very severe tropical cyclonic storms (VSCS) that develop freak waves in the oceanic water surface are responsible for numerous marine disasters. Extreme wave condition is considered as one of the major factors affecting naval and civilian shipping, offshore and coastal structures (Glejin et al. 2014).

In this regard, TC is considered as one of the most destructive natural disasters of the world. A global scenario of TC shows that its maximum occurrence is in the western Pacific Ocean and 7\% of the global TC (Neumann 1993) occur in the northern Indian Ocean (comprises of Arabian Sea and Bay of Bengal) which are the most deadly. Over the north Indian Ocean, formation of TC is highly seasonal with primary maximum in postmonsoon (October, November and December) and secondary maximum during pre-monsoon (April and May) (Mohanty et al. 2010). The ratio of frequency of occurrence of TC in the Bay of Bengal (BoB) and Arabian Sea (AS) is about 4:1 (Dube et al. 1997). Concentrating on the Indian coast, there are eight maritime states along the eastern and western coast of India that have deeply suffered from tropical cyclones (Alam et al. 2003). East coast of India is highly prone to cyclones that are generated in BoB. The orientation of the eastern Indian coastline and sudden decreases in the continental shelf of the east coast make the situation more complex by allowing the waves to

Keywords. Wave forecast; tropical cyclone; wave power; abnormality index; wave spectrum; MIKE 21 SW model. 
surge further causing heavy floods during storm conditions (Aboobacker et al. 2009). Among the east coast maritime states (Tamil Nadu, Andhra Pradesh, Odisha, West Bengal), Odisha and Andhra Pradesh are the most affected by the BoB cyclones. The constant increase of the economic activities in coastal waters, especially in the neighbourhood of the ports and harbours, thus demands an accurate wave forecasting in the coastal regions especially during tropical cyclones (Sandhya et al. 2014).

A convenient source for delivering the forecast products of wave parameters is the numerical wave prediction systems that run in operational mode. Such a system is very important to forewarn the users such as fishermen community and other commercial users in the coastal zones on the possible hazardous conditions during extreme weather events (Balakrishnan Nair et al. 2014). To accomplish this, the Earth System Science Organization-Indian National Centre for Ocean Information Services (ESSO-INCOIS), Hyderabad started quantitative Ocean State Forecast (OSF) service in 2005 by issuing forecasts of vital ocean parameters like significant wave heights, remotely generated waves (swells) and ocean surface winds, seven days in advance and at 3-hr intervals, with daily updates for the Indian coastal states. A wave forecasting system developed at OSF-INCOIS (www.incois. gov.in) is used to monitor and deliver the accurate wave forecast in the Indian Ocean region. It provides ocean state information on daily operational basis to users for smooth conduct of their operations. INCOIS is issuing high wave alerts during extreme weather events, as forecasted by numerical models. The alerts give information about significant wave height, swell wave height, wave period, wave direction and ocean surface winds. Most of the users utilize these forecasts as guidance for their daily operational activities and to ensure safe navigation (Balakrishnan Nair et al. 2013).

In this paper, we validate the wave forecasting system of INCOIS during the period of two VSCS occurred in the BoB, in the consecutive years 2013 and 2014. The post-monsoon BoB cyclones generally develop in the south Andaman Sea and move in the west-northwesterly direction initially. Further some of them continue to move in westnorthwesterly direction initially, and later move in the same direction or would recurve either after crossing the east coast of India or over the BoB itself (Subbaramayya et al. 1979).

In 2013 and 2014, there were two very severe cyclones Phailin and Hudhud which occurred around same period of October. These two cyclones were following the same track initially and the affected coastal areas were also same. This has given a chance to check the consistency of the wave forecast system for providing the accurate wave information during VSCS. The performance of the MIKE 21 spectral wave model (SW) has been analyzed using in-situ and satellite observations.

The paper is organized as follows: section 2 presents the details of the two cyclones which is then followed by data and methodology in section 3. Initial part of section 4 deals with forecast verification in the deep water followed by the validation in the shallow water and end of this section describes about the wave power during the VSCS. Finally conclusions are given in section 5 .

\section{Very severe cyclones - Phailin and Hudhud}

The destructive VSCS 'Phailin' had an 8-day life cycle from 6-14 October, 2013 (IMD report 2013). A cyclonic circulation that developed near Tenasserim coast on October 6 moved westward and later consolidated in the Andaman Sea as a depression early on October 8 near $12^{\circ} \mathrm{N}$ and $96^{\circ}$ E. Early on 9 October, as it intensified further, India Meteorological Department (IMD) declared it as a deep depression. The system further moved northwest towards BoB. It rapidly intensified in to a cyclone initially and subsequently in to a VSCS in the forenoon of 10 October over the east-central BoB. The VSCS crossed Odisha near Gopalpur around 0017 UTC on 12 October, 2013 with a sustained maximum surface wind speed of 200-210 km/hr gusting to $220 \mathrm{~km} / \mathrm{hr}$.

The devastating VSCS 'Hudhud' also had an 8-day life cycle from 6-14 October, 2014 (IMD report 2014). The VSCS 'Hudhud' formed in the morning of 6th October, 2014 as a low pressure area which lay over Tenasserim coast and adjoining north Andaman Sea. It turned into a depression on 7th October over the north Andaman Sea and the movement was west-northwestwards. In the morning of 8th October, it intensified into a cyclonic storm and crossed Andaman Islands near to Long Island between 0300 and 0400 UTC of 8th October. In the southeast BoB, its movement was westnorthwestwards. It intensified into a severe cyclonic storm in the morning of 9th October and further into a VSCS in the afternoon of 10th October. It reached a maximum intensity in the early morning of $12 \mathrm{th}$ with a maximum sustained wind speed of $180 \mathrm{~km} / \mathrm{hr}$ over the west central BoB off Andhra Pradesh coast. It crossed north Andhra Pradesh coast over Visakhapatnam between 0600 and 0700 UTC of 12th October, 2014 with the same wind speed. Figure 1 shows the study area and the tracks of the two VSCS. From the above description, it can be seen that the two VSCS happened in the same period with many similarities in its each stage of their intensification. This gives a unique chance 


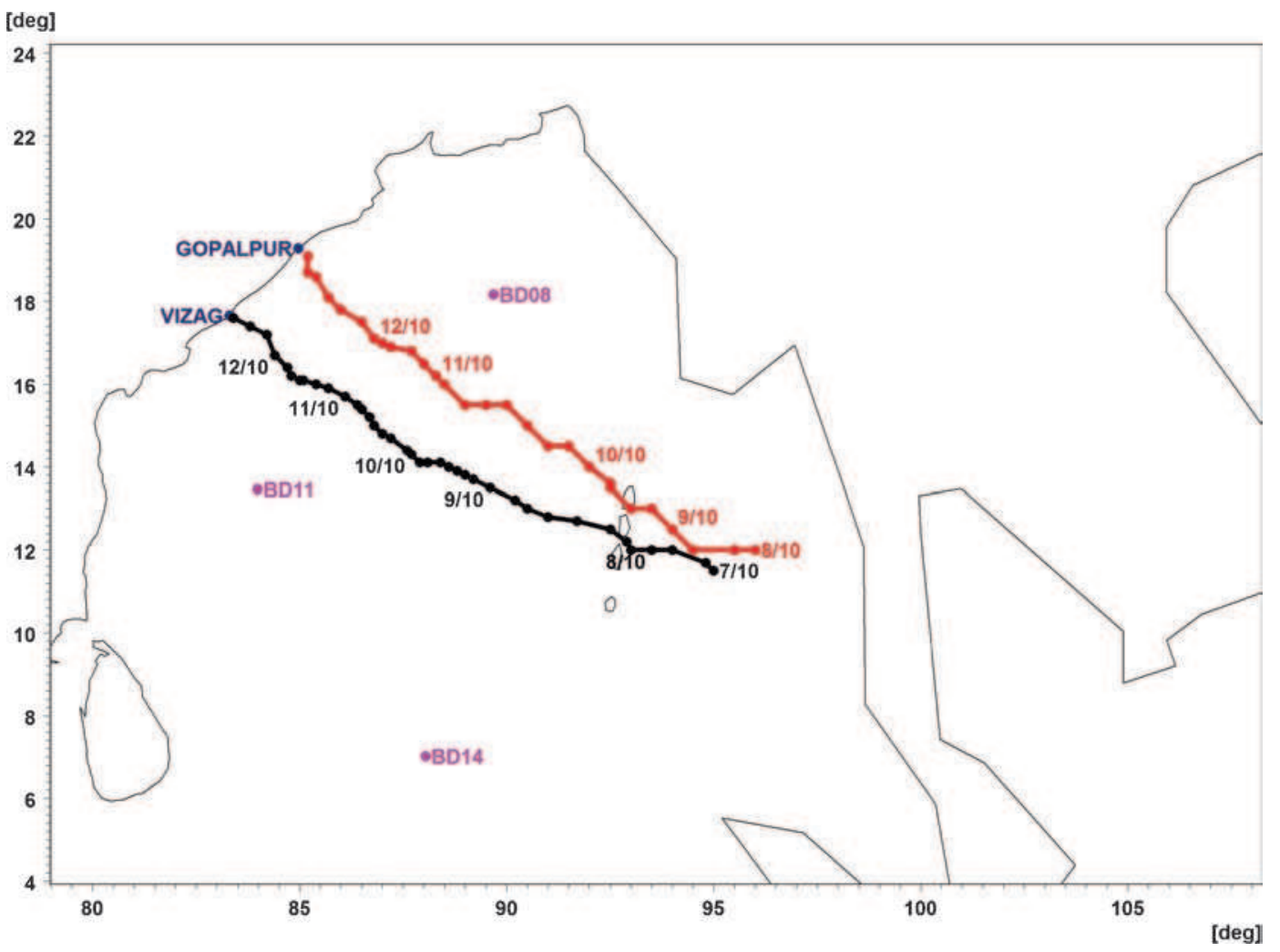

Figure 1. Track of the very severe cyclonic storms Hudhud (black) and Phailn (red) as per IMD records. Locations of moored and wave rider buoys are represented by pink and blue respectively.

to test the consistency in the performance of wave forecasting system during VSCS.

\section{Model and the data used for validation}

The wave fields for the comparison are generated using the ESSO-INCOIS operational MIKE21 SW model for both the VSCS. MIKE21 SW is a new generation spectral wind wave model, based on unstructured meshes, and is developed by Danish Hydraulic Institute (DHI 2014). The model simulates growth, decay and transformation of wind generated waves and swells in offshore and coastal areas. The use of unstructured mesh enhances accuracy of the wave model near the complex areas of the coastline. SW model is based on flexible mesh and therefore is particularly applicable for wave analysis both on regional and local scales which is very important in simulating cyclonegenerated wave fields (Remya et al. 2012). Model simulates the wave growth by the action of wind, non-linear wave--wave interaction, dissipation due to white-capping, bottom friction and depthinduced wave breaking, refraction and shoaling due to depth variations, wave-current interaction and the effect of time varying water depth. Description of all source functions and the numerical methods used in the model are elaborated in Sorensen et al. (2004).

In the present study, we have used the SW model domain from $60^{\circ} \mathrm{S}-30^{\circ} \mathrm{N} ; 30^{\circ}-120^{\circ} \mathrm{E}$, though our area of interest is BoB (figure 1). Many recent studies show that swells from the southern Indian Ocean significantly modify the wave climate in north Indian Ocean (Remya et al. 2012; Sabique et al. 2012; Nayak et al. 2013). Hence, we extended the domain up to $60^{\circ} \mathrm{S}$ so that swells generated at southern ocean were properly simulated by numerical model. As far as the wave modelling is concerned, most challenging task is forecasting of wave height during tropical cyclone. We have carried out number of experiments by changing spatial and spectral resolutions of the model domain. The optimum spatial resolutions chosen for the BoB region were from $0.25^{\circ}, 0.15^{\circ}$ and $0.05^{\circ}$ from Open Ocean to the coastal areas. A coarse mesh of $1^{\circ}$ was applied in the southern Indian Ocean region. Different bathymetry datasets of Etopo $5\left(30^{\circ}-120^{\circ} \mathrm{E}, 60^{\circ}\right.$ $\left.\mathrm{S}-0^{\circ}\right)$, Etopo $2\left(95^{\circ}-120^{\circ} \mathrm{E}, 0^{\circ}-30^{\circ} \mathrm{N}\right)$ and modified etopo $2\left(30^{\circ}-95^{\circ} \mathrm{E}, 0^{\circ}-30^{\circ} \mathrm{N}\right)$ are used in the model domain.

European centre for medium range weather forecast (ECMWF) wind fields with a spatial resolution of about $0.25^{\circ} \times 0.25^{\circ}$ and temporal resolution of $3 \mathrm{hr}$ are used as forcing fields to the wave model. 
The quality of the ECMWF wind forecast depends on the assimilation of the real time observations such as satellite instruments, weather stations, ships, buoys and other components in the weather prediction model. More details on ECMWF winds can be obtained from ECMWF user guide (Andersson 2013). Further SW model was simulated by ECMWF winds for Hudhud (7-14 October, 2014) and Phailin (7-14 October, 2013) cyclones. A spin up of 15 days has been done to account the swell waves. As a part of our study, we have simulated the model with different directional resolutions, i.e., 24, 36 and 48 bins keeping frequency resolution constant. Significant change was not seen in the spectra with the increase in the spectral resolution when it is validated with observations. Hence, for the present study, we have used 24 directional resolutions and 28 frequency resolutions in the spectrum. Since the focus of this study is to compare the model-derived wave fields with observations, we have used all the in-situ observations near the cyclone tracks. Buoy locations are shown in figure 1. Data from the open ocean moored buoys (BD08, BD11, BD14) are obtained from Earth System Sciences Organization (ESSO), National Institute of Ocean Technology (NIOT) and Directional Wave Rider Buoys (DWRB) are obtained from the Earth System Sciences Organization (ESSO)-Indian National Centre for Ocean Information Services (INCOIS). In cases of Hudhud and Phailin, DWRB was available at the landfall locations Visakhapatnam and Gopalpur respectively. In addition to the $i n$-situ observations, satellite altimeter data are also used for the study. AltiKa, the first Ka band altimeter, measured $\mathrm{Hs}$ is used for validating the model results. The altimeter data is obtained from TUDelft RADS database (http://rads.tudelft.nl/rads/rads.shtml) (Schrama et al. 2000) with up-to-date corrections applied.

\section{Results and discussions}

\subsection{Forecast verification in the deep water}

The performance of the operational wave forecasting system at ESSO-INCOIS during Hudhud and Phailin cyclones is studied by comparing wave forecast with in-situ observations and satellite measurements. Our focus was mainly on forecasting storm peaks and representation of maxima or extreme wave heights in the study area as it always pose a threat to navigation and other offshore activities. Initially, we focused on the wave evolution in the buoy locations. Figure 1 shows that BD08 and BD11 were near to the cyclone tracks and BD14 location away from tracks. The growth and decay of waves were very clear in the buoy BD08 during Phailin. Similarly during Hudhud,
BD11 was near to the track and the wave evolution was very clear at this location. A time series of wave and wind parameters are shown in figure $2(\mathrm{a}-\mathrm{g})$ for BD08 (Phailin) and figure 2(h-n) for BD11 (Hudhud), respectively. Any error in the input wind field will result in an error in the computed wave field because wind waves are sensitive to small variations in the forcing wind fields (Cavaleri 1994). The accuracy of the forecast wave fields depends upon the accuracy of the forecast winds and hence we validated the forecast winds with in-situ wind measurements in the BD08 and BD11 locations.

During Phailin cyclone, maximum forecasted winds observed along the track was $27 \mathrm{~m} / \mathrm{s}$ on 12 th October, 2013 UTC at $85.49 \mathrm{E}, 18.50 \mathrm{~N}$. Figure 2(a, b) shows the comparison of winds at BD08 during Phailin cyclone. The geographic location of BD08 shows northwest $\mathrm{BoB}$ which is predominated by weak winds $(<10 \mathrm{~m} / \mathrm{s})$ with varying directions from SW to W during October. Both wind speed and direction changed from 9th October onwards, i.e., as the cyclone approaches to this location, wind speed has increased slowly and reached a maximum of $15 \mathrm{~m} / \mathrm{s}$. The wind speed remained high till $12 \mathrm{th}$ October and decreased slowly afterwards. Predominant wind direction was NW to $\mathrm{N}$ on 9-11th October, and changed to SE to S after 11th October onwards. Figure 2(a) shows that the ECMWF wind fields are able to pick the rapid variations in the cyclonic wind. The ECMWF wind forecast is also showed a maximum wind speed of $16 \mathrm{~m} / \mathrm{s}$ at this location but with a lag of $3 \mathrm{hr}$. Also, the changes in the wind direction were very clear in the forecast and this was in good agreement with the observed changes.

Accurate forecast wind in principle should produce accurate wave fields. Figure 2 shows the comparison of wind and wave parameters at BD08 and BD11 locations during Phailin and Hudhud periods, respectively. The wave parameters used for the comparison are significant wave height (Hs), swell wave height (Hss), wind sea wave height (Hsw), maximum wave height (Hmax) and peak wave period (Tp). The growth and decay of wave fields observed at BD08 during Phailin was clearly mimicked by the forecasted wave field and it could be achieved due to the accurate wind fields. Figure 2(c) shows that before the arrival of extreme event (Phailin), BD08 was predominated by waves of $1 \sim 2 \mathrm{~m}$, i.e., on $7-8$ th October, 2013. As cyclone approaches to the location, Hs increased gradually from 9th October, 2013 onwards and reached its peak value on 12th October, 2013. Maximum Hs forecasted by the model was $5.85 \mathrm{~m}$ on 12 th October, 0900 UTC, whereas observation shows maximum $5.91 \mathrm{~m}$ on 12 th October, 0600 UTC. This was due to the lag observed in the wind forecast. All forecasted wave parameters 


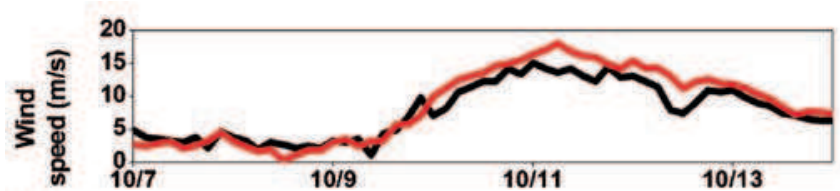

(a)

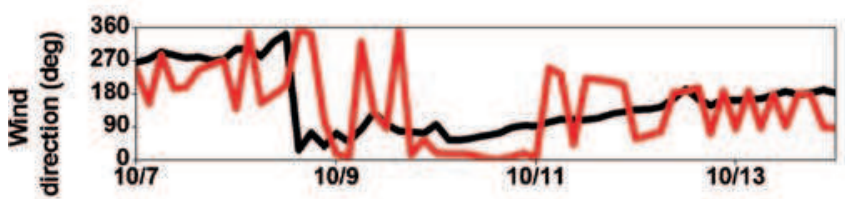

(b)

(c)

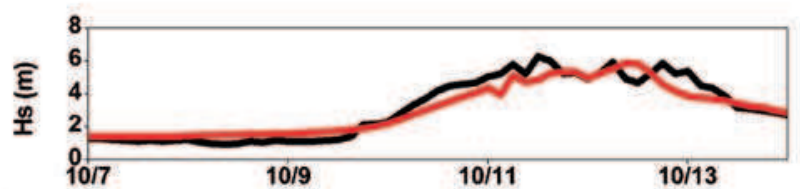

(d)

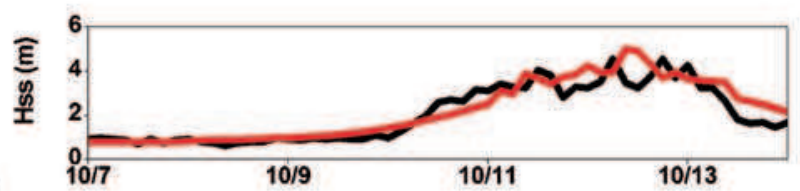

(e)
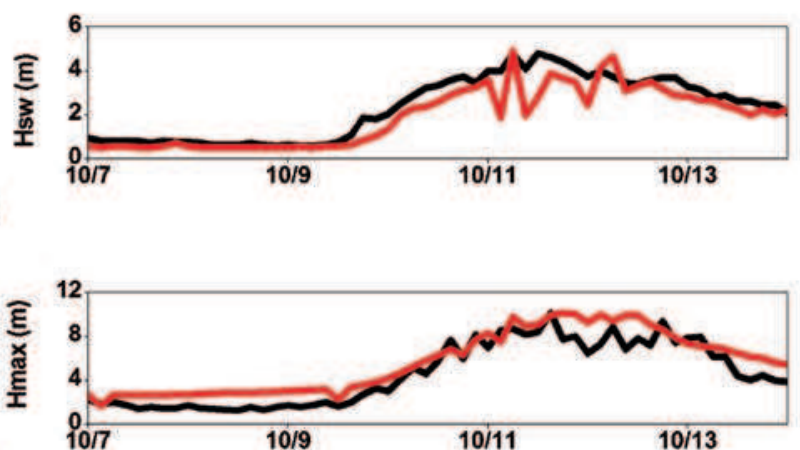

(f)

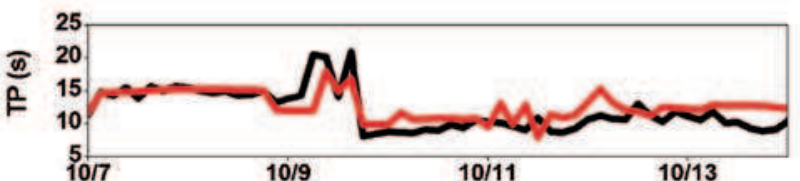

$(\mathrm{g})$

Figure 2. Comparison of measured and forecasted wave parameters during Phailin and Hudhud cyclones. Plots (a-g) and $(\mathbf{h}-\mathbf{n})$ refer to BD08 and BD11, respectively.

both observed and forecasted showed peak values on 12th October, 2013, i.e., during landfall of the cyclone. After landfall, the Hs (observed and forecasted) decreased gradually. The swell waves were more compared to wind sea as the location was not exactly on the cyclone track. The peak wave period shows a clear transition from high period swells ( $\sim 15 \mathrm{~s})$ to young swells ( 10 s) during the event.

During Hudhud cyclone, maximum forecasted winds obtained was $(35 \mathrm{~m} / \mathrm{s})$ along the track on

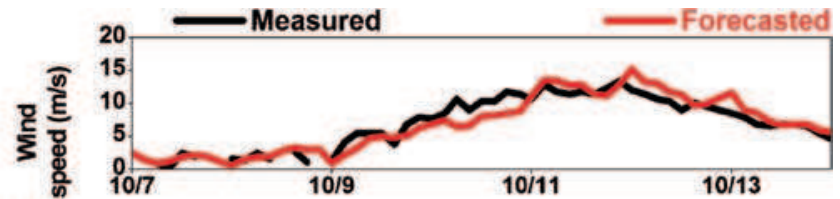

(h)

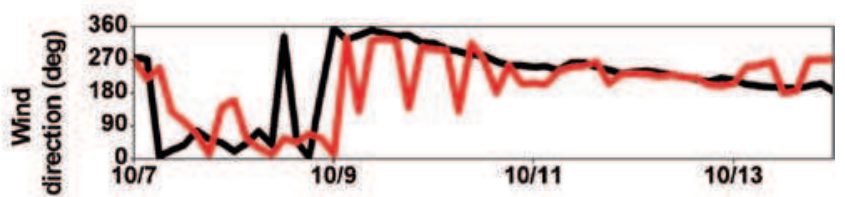

(i)

(j)

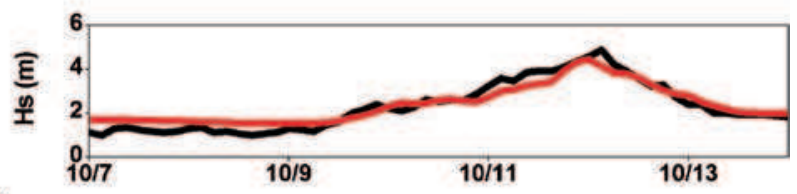

(k)

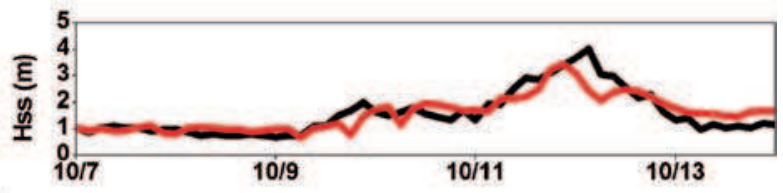

(1)

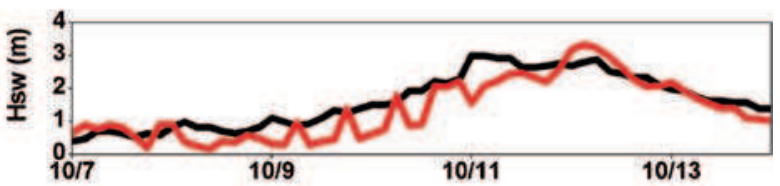

$(\mathrm{m})$
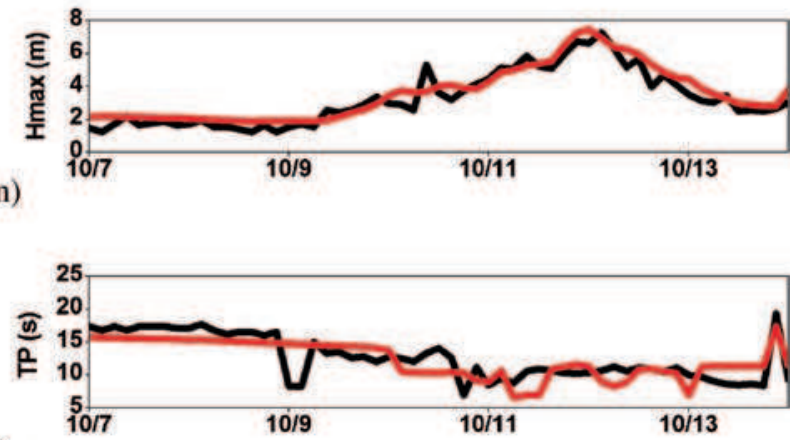

(n)

12th October, 2014 at $(83.51 \mathrm{E}, 17.48 \mathrm{~N})$. BD11 buoy was near as well as on the left side of Hudhud track. Geographic location of BD11 shows western $\mathrm{BoB}$ which is predominated by weak winds before the passage of cyclone. As cyclone approached the location, wind strengthened slowly, from 9th October onwards and reached at a peak of $12 \mathrm{~m} / \mathrm{s}$ on 12 th October, then decreased afterwards (figure $2 \mathrm{~g}$ ). The forecast wind speed was around $15 \mathrm{~m} / \mathrm{s}$ on 12 th October. Wind direction shows 
predomination of northeasterly winds before the cyclone passage and direction changed to southwest from 9th October onwards when the cyclone approached the location. Similar to the case of VSCS Phailin, wind fields were in good agreement during the VSCS Hudhud.

Figure 2(h) shows that before the arrival of extreme event (Hudhud), BD11 was predominated by waves of 1-2 m (on 7th-8th October, 2014). Hs has increased from 9th October, 2014 onwards and reached its peak value on 12th October, 2014 when the cyclone approached the location. Maximum significant wave height forecasted by the model was $4.45 \mathrm{~m}$ on 12 th October, 0000 UTC, whereas observation shows maximum $4.86 \mathrm{~m}$ on 12 th October, 0300 UTC. Figure 2(k, l) shows that both wind sea and swell equally contributed to this high wave. The transition from high period swells

Table 1. Peak values observed and forecasted during Hudhud and Phailin.

\begin{tabular}{lccc}
\hline Buoy & Wave parameter & Observed $(\mathrm{m})$ & Forecasted $(\mathrm{m})$ \\
\hline BD11 & Hss & 4.04 & 3.44 \\
(Hudhud) & Hsw & 2.87 & 3.34 \\
& Hmax & 7.26 & 7.48 \\
BD08 & Hss & 4.57 & 5.03 \\
(Phailin) & Hsw & 3.75 & 4.66 \\
& Hmax & 8.90 & 9.99 \\
\hline
\end{tabular}
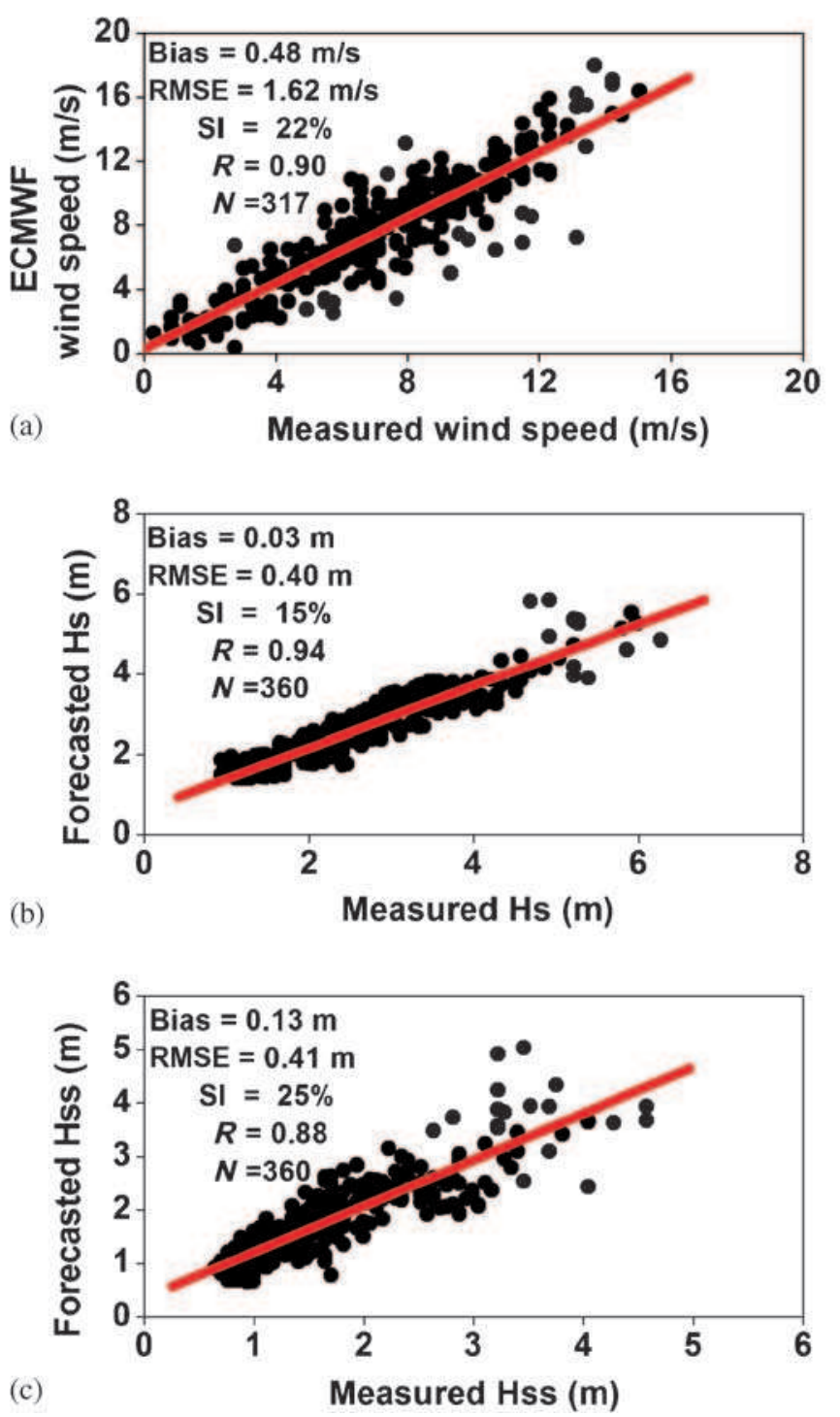
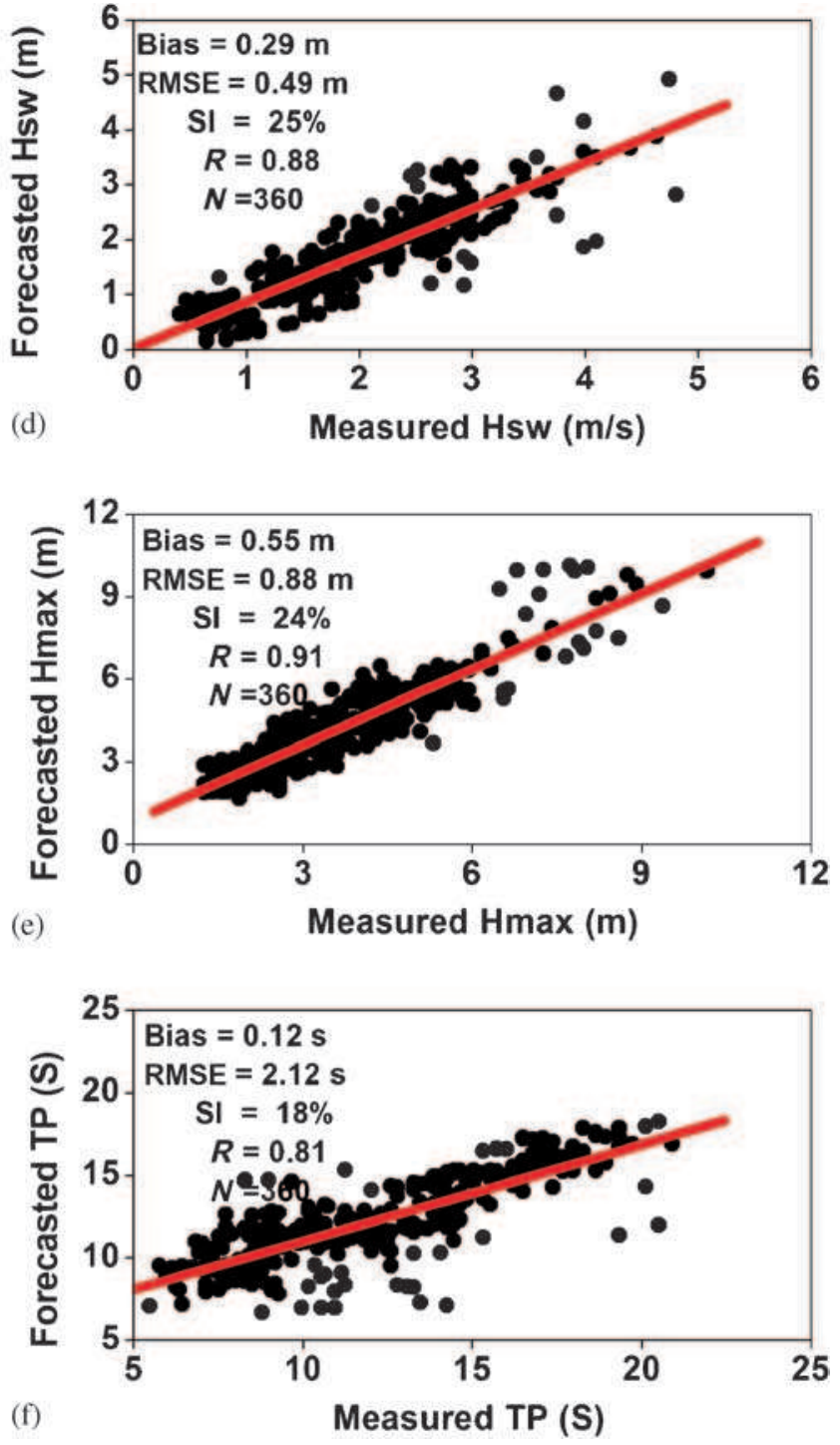

Figure 3. Wave forecast comparison in the BOB using moored buoys. 
to cyclone generated swells was visible at this location also (figure $2 \mathrm{n}$ ). All forecasted wave parameters have shown peak values on 12th October, 2014, i.e., during landfall of the cyclone. After landfall, Hs (observed and forecasted) decreased gradually. Table 1 shows all the peak values of observed and forecasted during Hudhud and Phailin periods.

The time series plots show the ability of the model in simulating the rapidly varying wave fields. To get a quantitative picture of the model performance, the model error statistics (Bias, RMSE, SI and correlation) has been calculated using the four deep water buoys for both VSCS together. Wave forecast comparison shows an excellent agreement of ESSO-INCOIS wave forecast with observations during extreme conditions (figure 3 ).

Further, we have computed the error statistics between observed and forecasted wave parameters using formulas from equations (1-4). All the wave parameters show low scatter index $(<26 \%)$ and high correlation $(>0.87)$. There was marginally no bias in the Hs and bias for other parameters ranging from $0.13-0.55 \mathrm{~m}$. Due to the sparse buoy measurement, we have also made use of the satellite altimeter, AltiKa, measurements of wind speed and wave height available in the study area for the forecast verification (figure 4).

$$
\begin{aligned}
\text { Bias } & =\sum_{i=1}^{N} \frac{1}{n}\left(M_{i}-B_{i}\right), \\
\mathrm{RMSE} & =\frac{1}{n} \sqrt{\sum_{i=1}^{N}\left(M_{i}-B_{i}\right)^{2},}
\end{aligned}
$$
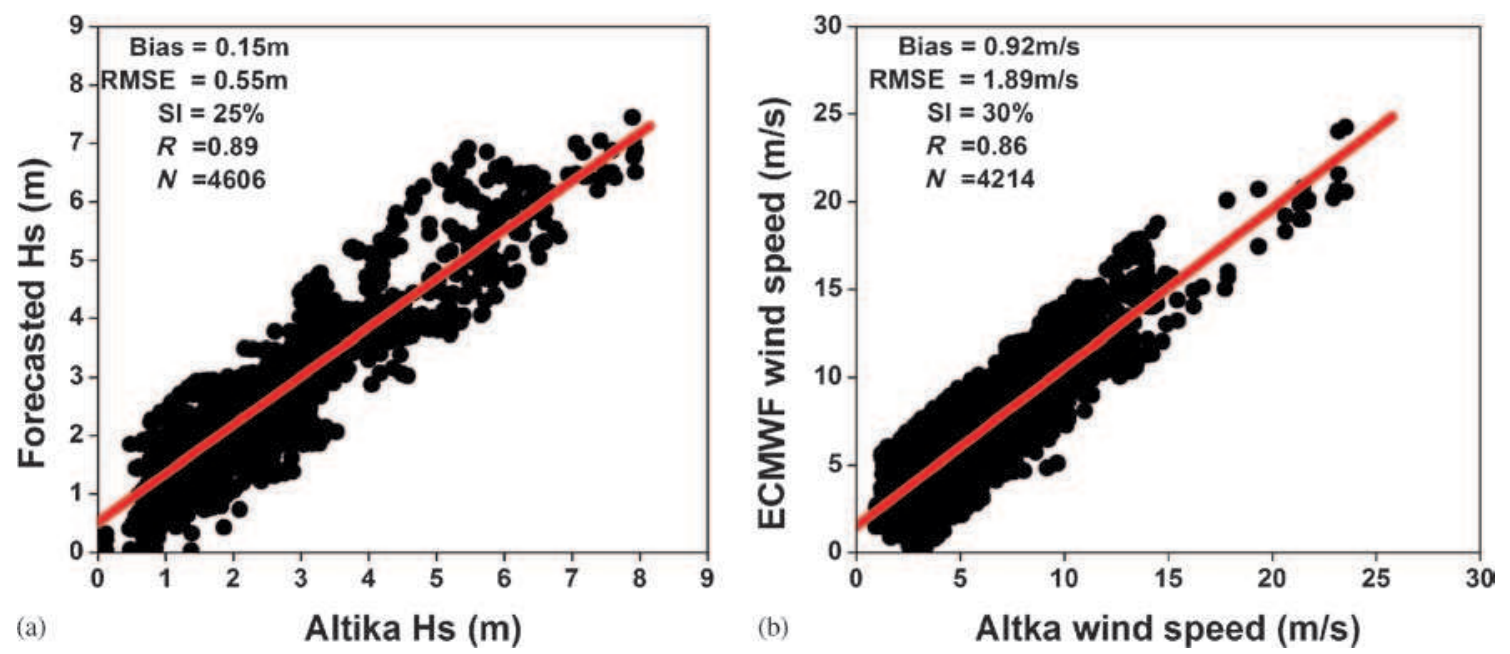

Figure 4. Wave forecast comparison in the BoB using AltiKa passes during Hudhud and Phailin cyclones.

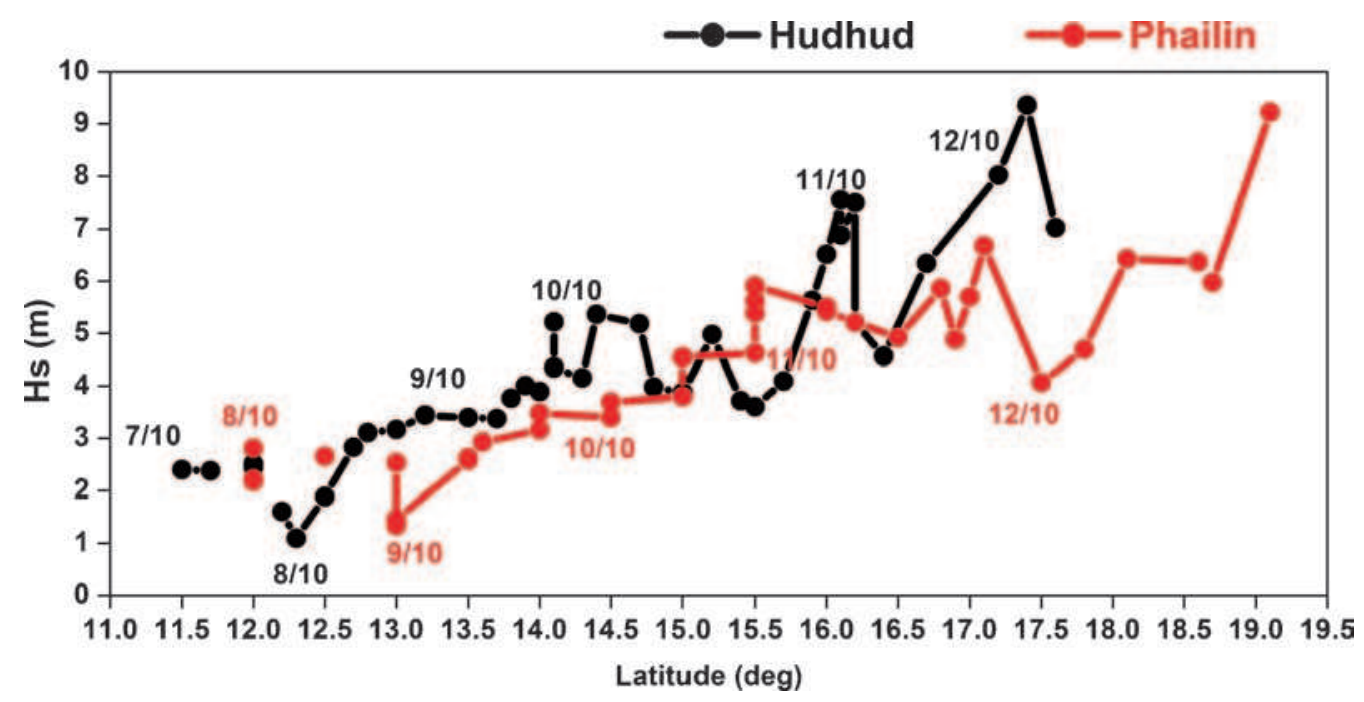

Figure 5. Variation of Hs with latitude along the track of the Hudhud and Phailin cyclones. Black and red lines indicate the track of Hudhud and Phailn, respectively. 


$$
\begin{gathered}
\mathrm{SI}=\frac{\mathrm{RMSE}}{\bar{B}} \\
R=\frac{\sum\left(M_{i}-\bar{M}\right)\left(B_{i}-\bar{B}\right)}{\sqrt{\sum_{i=1}^{N}\left(B_{i}-\bar{B}\right)^{2}} \sqrt{\sum_{i=1}^{N}\left(M_{i}-\bar{M}\right)^{2}}} .
\end{gathered}
$$

The collocation resulted more than 4000 points and compared with forecasted outputs for both VSCS. The wind speed comparison shows an overestimation of wind around $1 \mathrm{~m} / \mathrm{s}$ and that resulted a small positive bias in wave height also. Our comparison shows good agreement of $\mathrm{Hs}$ and wind speed with AltiKa passes (figure 4). The statistics shows the low SI which were in the range of $25-30 \%$ and high $R(0.86-0.89)$ in the BoB during extreme conditions for both winds and waves. The high correlation $(\sim 0.9)$ in the wave shows that the model is able to pick the rapid variations of the cyclonic wave fields. The model error statistics of the comparison with buoy as well as the altimeter measurements shows that the wave forecast in the open ocean is accurate enough.

We have evaluated the variation of $\mathrm{Hs}$ with latitude for both the cyclones (figure 5). From figure 5 , it is clear that during initial stages (7th and 8th October) the track of the cyclones were nearly same, i.e., within the vicinity of the lay centered at $12^{\circ} \mathrm{N}$ and $92^{\circ} \mathrm{E}$ and deviated further intensifying into cyclonic storm (9th October). To get more understanding on forecasted wave heights, we analyzed the Hs along the track with varying latitudes. During initial stages (i.e., 7th October Hudhud and 8th October Phailin), Hs was in the range of
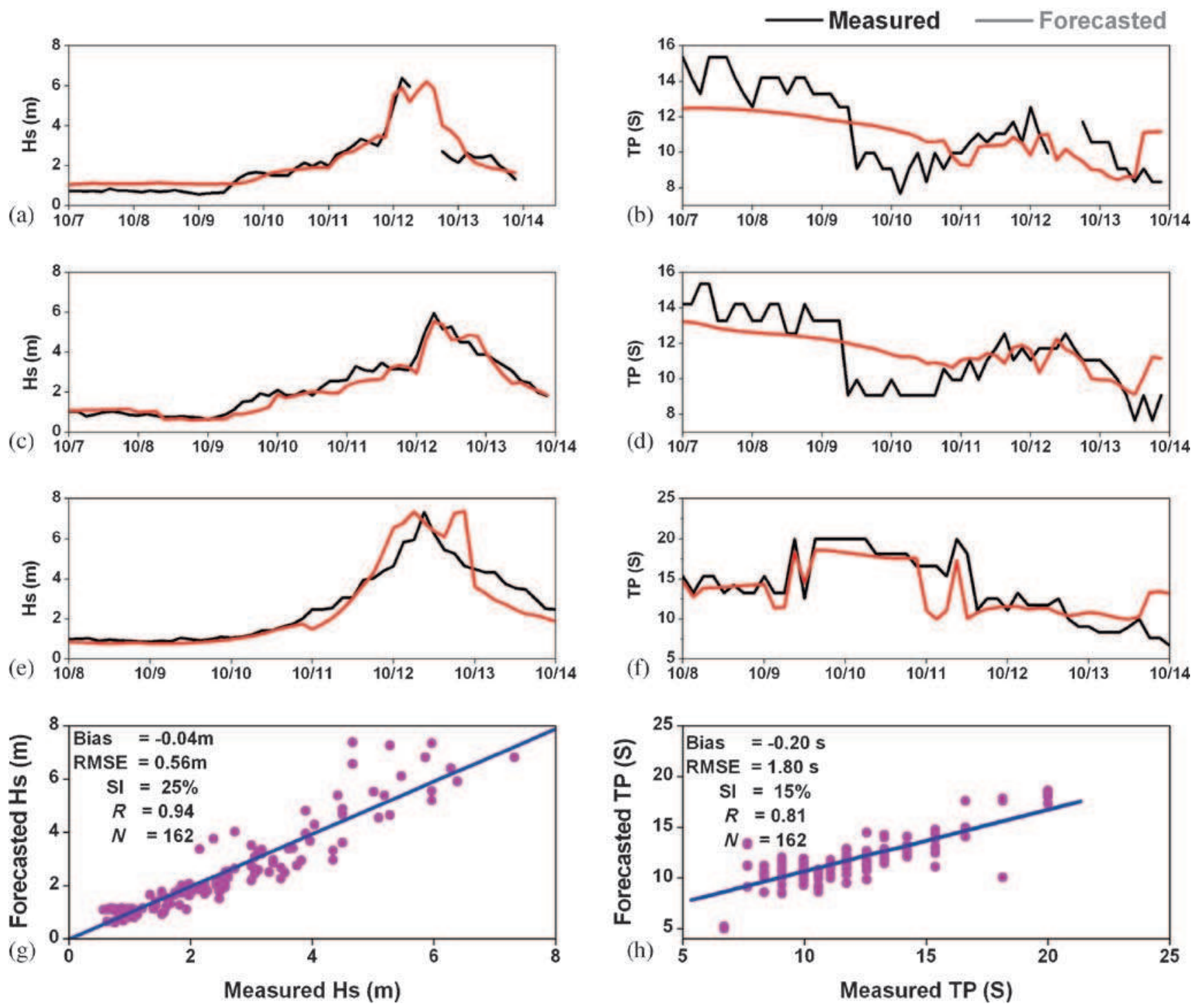

Figure 6. Comparison of wave forecast with DWRB network along the east coast. Plots (a, b) and (c, d) show comparison at Visakhapatnam and Gopalpur locations, respectively, during Hudhud cyclone. Plot (e, f) refers the comparison at Gopalpur during Phailin cyclone. Plot $(\mathbf{g}, \mathbf{h})$ shows bulk statistics computed at coastal areas for both cyclones. 
2 3 $\mathrm{m}$. This may be because both cyclones were in the depression stage but after crossing $13^{\circ} \mathrm{N}$, both cyclones were intensified and shown higher wave heights. Along the track it is observed that Hudhud wave heights were slightly higher than that of Phailin. Hs along the Phailin track have undergone rapid variations due to the variations of winds associated with the cyclone. Hudhud and Phailin made landfall at $17.5^{\circ} \mathrm{N}$ and $19^{\circ} \mathrm{N}$, respectively. Both cyclones have crossed wave height $>9 \mathrm{~m}$ during landfall.

\subsection{Forecast verification in the shallow water}

In the shallow water, exactly at the landfall locations of both VSCS, ESSO-INCOIS DWR buoys were available for forecast verification. The landfall locations of the VSCS Phailin and Hudhud were at Gopalpur and Visakhapatnam. The trend of Hs and TP is analyzed at the Gopalpur location for the VSCS Phailin and is shown in figure 6(e-f). It was found that $\mathrm{Hs}$ was approximately $1 \mathrm{~m}$ until 10th October and showed an increasing trend afterwards. Gopalpur was on the right side of the cyclone track. So the location was receiving cyclone generated swells very much prior to the landfall. The highest Hs observed was $7.32 \mathrm{~m}$ at
0900 UTC on 12th October, just before the buoy drifted due to high currents. The forecast Hs was able to pick this high peak and the value was $7.34 \mathrm{~m}$ at Gopalpur during landfall. We have not compared wave forecast at Visakhapatnam due to unavailability of DWRB data.

During Hudhud cyclone period, both Visakhapatnam and Gopalpur buoys were available for the forecast verification (figure $6 \mathrm{a}-\mathrm{d}$ ). Gopalpur was lying on the right side of the cyclone track and hence it was receiving high waves continuously from 9th-13th October. This is due to anticlockwise rotation of the cyclones in the northern hemisphere and right side region of the cyclonic storms are exposed to a longer wind forcing. This will cause high waves in the right side of the track (Parise and Farina 2014). Gopalpur received a maximum Hs of $6 \mathrm{~m}$ on 12th October 0006 UTC during the landfall time. Though the cyclone made landfall at Visakhapatnam, the right side regions were hit by its furious waves continuously for 5 days from 9-13. This was seen during Phailin also. The forecast shows maximum $\mathrm{Hs}$ of $5.55 \mathrm{~m}$ at Gopalpur. The Visakhapatnam location started receiving the cyclone waves on 9th October 11:00, $5 \mathrm{hr}$ later than Gopalpur. The wave heights were less compared to Gopalpur till 11th October 11:00 and then the wave heights were continuously increasing and
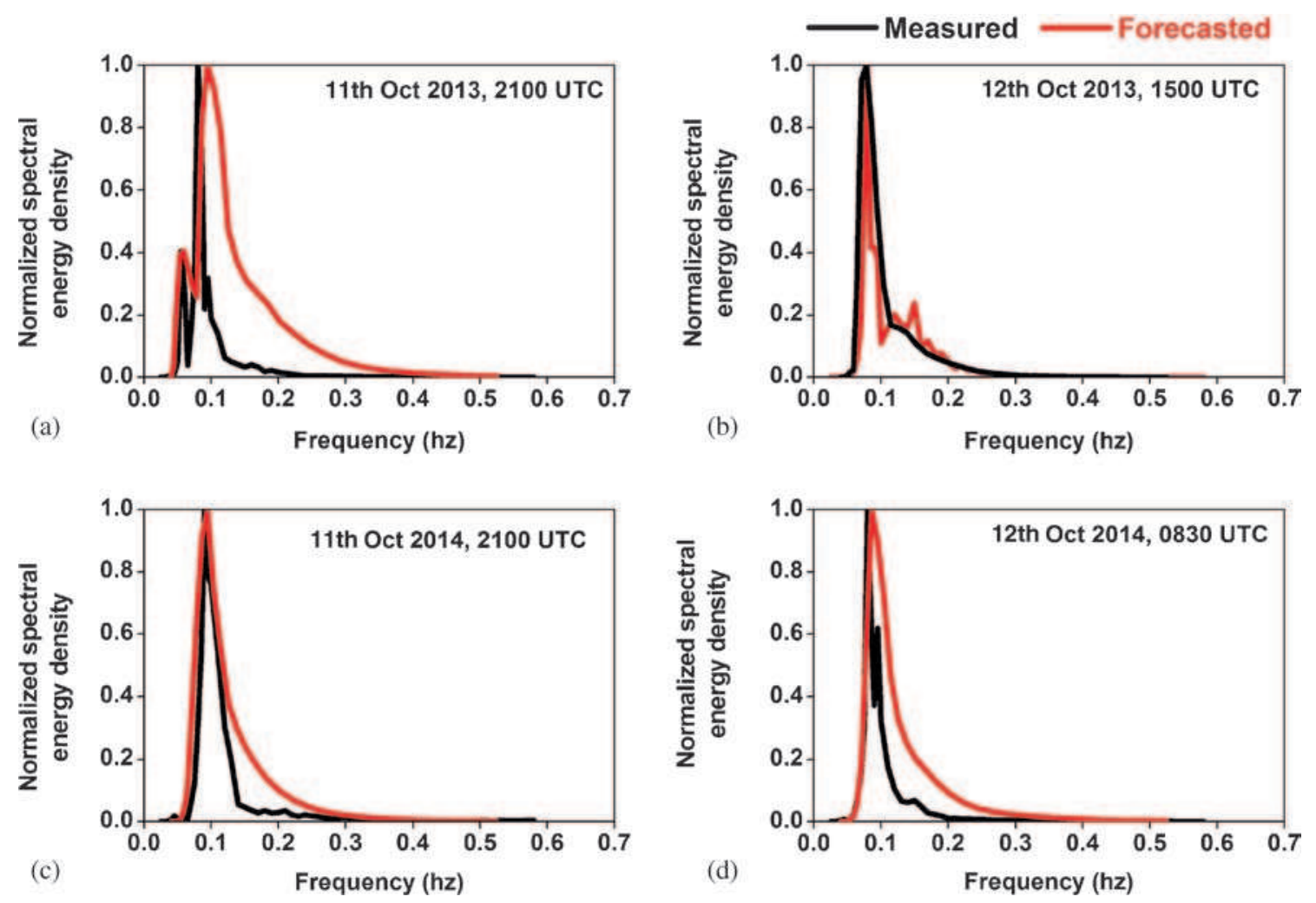

Figure 7. Comparison of measured and forecasted one-dimensional wave spectrum at coastal areas. Plots (a), (b) refer to Gopalpur during Phailin and (c), (d) refer Visakhapatnam during Hudhud. 
it reached to a maximum of $6.38 \mathrm{~m}$ (observed) and $5.91 \mathrm{~m}$ (forecasted) on 12th October 2014, 0300 UTC with a peak wave period value of $11 \mathrm{~s}$. Bulk statistics has been computed using wave rider buoy measurements (Visakhapatnam, Gopalpur) during Hudhud and Phailin. Model error statistics has been calculated in a similar way as described in the earlier section 4.1. The statistics shows that the wave parameters have errors $(<26 \%)$ and $R$ $(>0.80)$ along the east coast. Both Hs and TP have marginally no bias with low RMSE. The statistics confirms the good agreement of the wave forecast with observations during extreme conditions.

Figure $7(\mathrm{a}-\mathrm{d})$ shows the comparison between forecasted and measured one-dimensional frequency spectra at Gopalpur (Phailin) and Visakhapatnam (Hudhud) locations. Comparison shows that forecasted spectra are single-peaked due to extreme events prevailed in this region. Comparison at Gopalpur (figure $7 \mathrm{a}-\mathrm{b}$ ) shows peaks at frequencies below $0.1 \mathrm{~Hz}$ which are well simulated by the model indicating the dominance of long period waves. Further, slight shift in the peak frequency of the forecasted spectrum noticed on 11th and 12th October which can be attributed to the errors associated with the forcing fields. At Visakhapatnam, forecasted spectrum showed good agreement with measured spectrum, i.e., peak frequencies of both the measured and forecasted spectra are identical which confirms the accurate prediction of swell and wind seas during Hudhud cyclone period (figure $7 \mathrm{c}-\mathrm{d}$ ).

\subsection{Freak waves and wave power at the coastal regions}

The study of the characteristics of the freak waves during VSCS is also important as they can cause damage to offshore structures and their wave heights can lead to ship accidents. Freak waves are relatively rare, large and spontaneous oceanic surface waves whose heights are larger than maximum wave height expected for a given sea state. Freak waves have been observed all over the world oceans and their characteristics are studied in the Mediterranean Sea, the Pacific, the Atlantic and some parts of the Indian Ocean (Glejin et al. 2014).

An attempt has been made to study the generation of freak waves at all moored and wave rider buoy locations. Freak waves are also called as abnormal waves and identified by their abnormality index $(\mathrm{ABI})$, i.e., the ratio of maximum wave height $(\mathrm{H})$ to significant wave height $(\mathrm{Hs})$ would be larger than two $(\mathrm{H} / \mathrm{Hs}>2)$ (Ponce de León and Guedes Soares 2014). Measured data of significant wave height and maximum wave height are
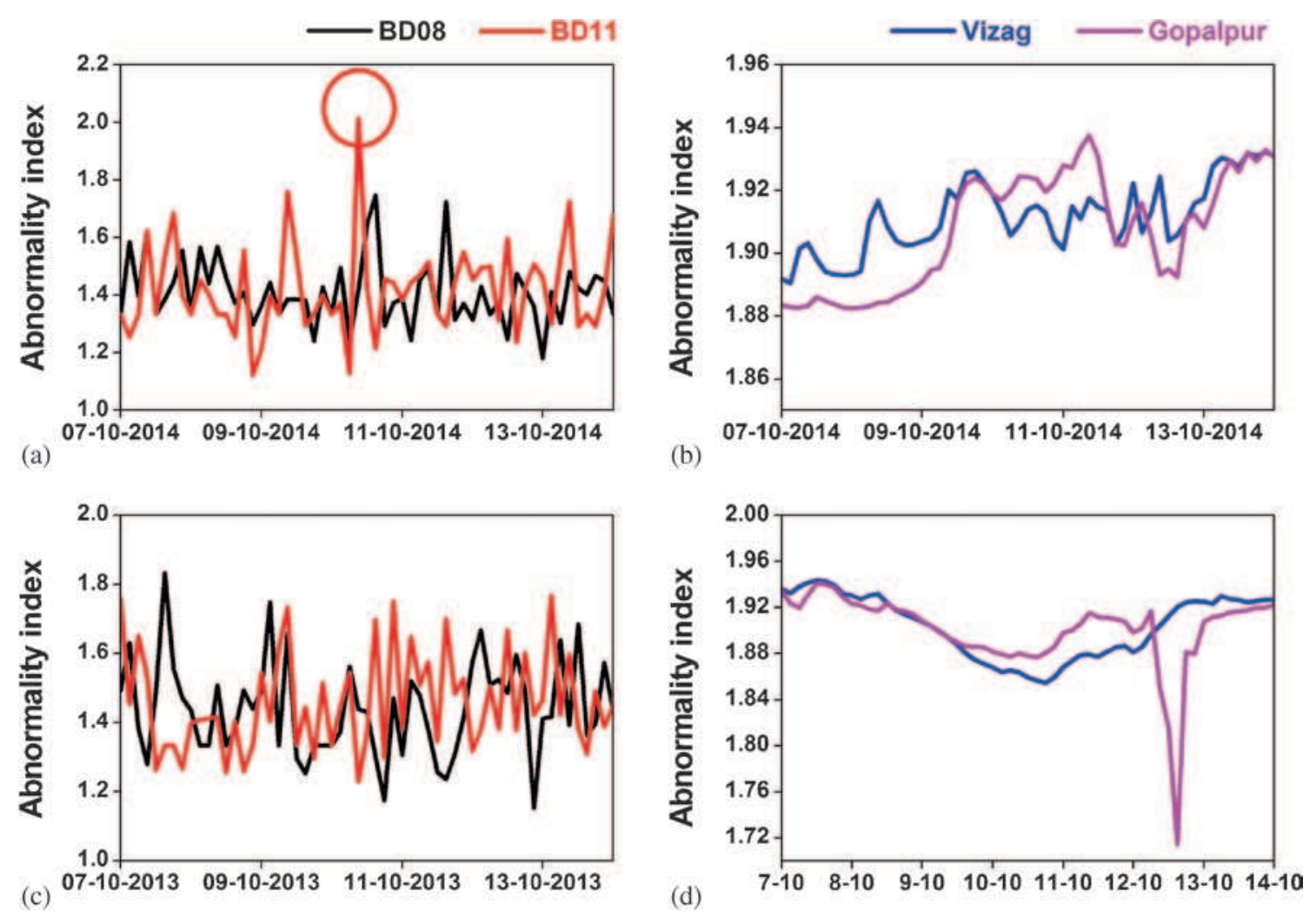

Figure 8. Time series plots of abnormality index at moored and wave rider buoy locations. Plots (a), (b) refer to Hudhud and (c), (d) refer to Phailin, respectively. Freek wave observed at BD11 during Huhud period was marked with red circle. 
available at all moored buoy locations. Hence, we have computed ABI with measured data at moored buoy locations. But at shallow water locations measured data of maximum wave heights were not available. Hence, we have computed the ABI using forecasted outputs. The plots are shown in figure 8 . From figure 8 , it is observed that rough waves of $\mathrm{ABI}(>2)$ were found at BD11 during Hudhud and no rough waves were observed during Phailin cyclone (figure 8c-d). Near the coastal areas, though there was no rough waves observed but it is interesting to note that Gopalpur has shown high ABI from 10-12th October, 2014 than Visakhapatnam (figure 8b). During this period, the location was receiving mainly cyclone-generated swells. Swell waves have high wave length and in the shallow water the wave height increases due to shoaling. This may be one of the reasons for high ABI. Another reason may be the refraction and
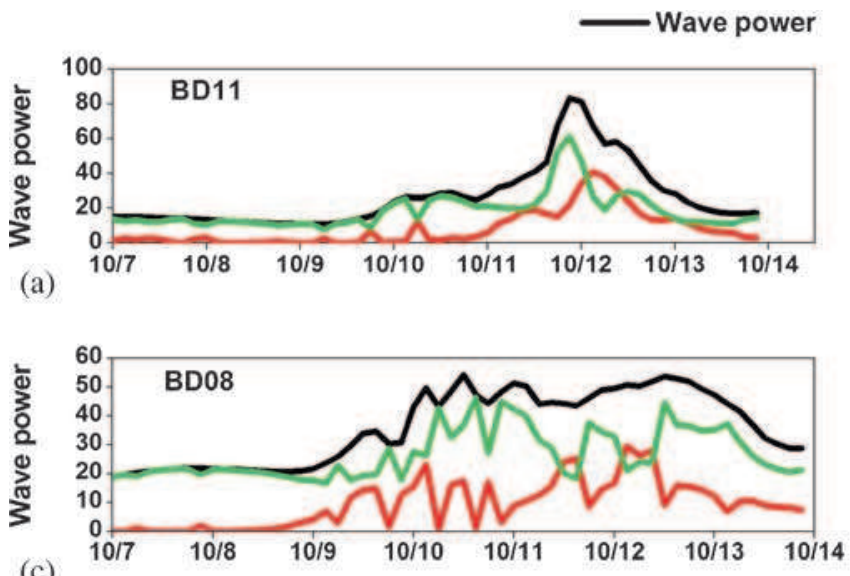

(c)
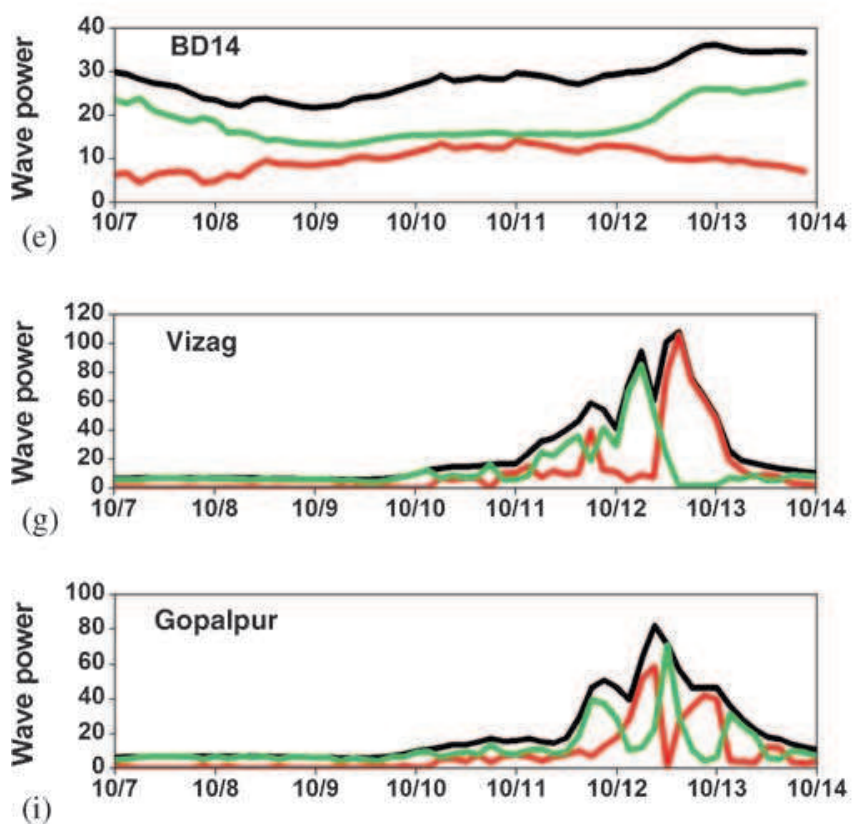

orientation of the coastline $\left(45^{\circ}\right.$ north) which plays a major role in breaking the waves near the coast. This was observed during Phailin period also, i.e., from 10-12th October, 2013 (figure 8d) but there was sharp decrease in ABI on 12th October 2013, $09 \mathrm{hr}$ onwards.

When cyclone make landfall near east coasts, the entire stretch of the coastal areas are greatly affected because of associated storm surge and high-wave power events. The high wave power associated with TC during landfall significantly causes the coastal erosion that can results in long-term changes in the coast line.

$$
\text { Wave power }=\rho g C_{g} E \text {, }
$$

SW model computes the wave power using equation (5) (DHI 2014). Here $\rho$ is the density of the water, $g$ is acceleration due to gravity, $C_{g}$ is the
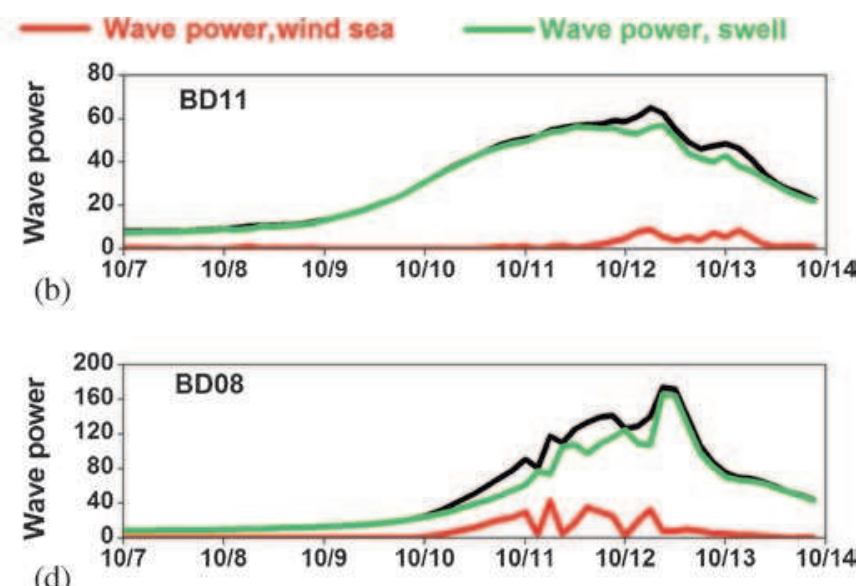

(d)
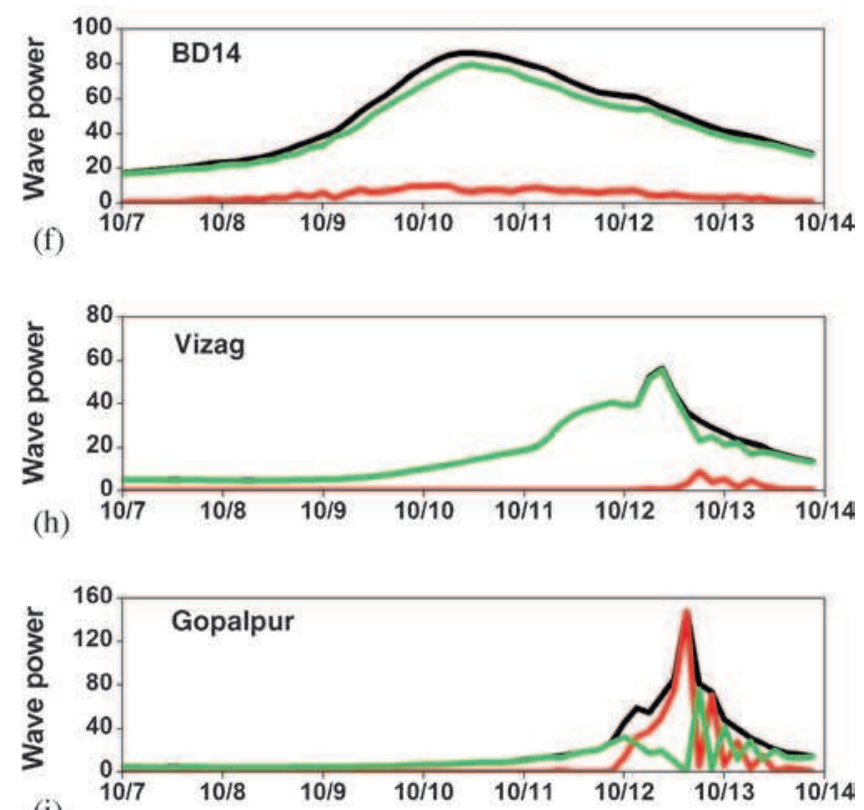

(j)

Figure 9. Time series plots of wave power computed by SW model at moored and wave rider buoy locations. Plots (a, c, e, g, i) refer to Hudhud and (b, d, f, h, j) refer to Phailin. 
group velocity and $E$ is the energy density of the harmonic wave. More details are given in DHI scientific documentation (DHI 2014).

Time series plots of wave power forecasted by the SW model at moored and wave rider buoys during Hudhud and Phailin are shown in figure 9. During Hudhud period, forecasted wave power was highest at BD11 as the buoy location was near to the cyclone track. At this location, forecasted wave power has increased from 10th October, 2014 onwards and reached peak value $(83 \mathrm{~kW} / \mathrm{m})$, i.e., on 12th October, 2014 during landfall and decreased gradually afterwards. Among the two shallow water locations of Visakhapatnam and Gopalpur, wave power forecasted has shown highest peak vales $(108 \mathrm{~kW} / \mathrm{m})$ on 12th October, 2014 at Visakhapatnam. As the cyclone made landfall at this location, it has shown highest wave power when compared to other buoy locations. From the time series plots it was observed that the wave power of the wind sea was greater than that of the swell at Visakhapatnam, during landfall of Hudhud. This is because of strong winds persisting near the coast at that time. Moreover from figure 9 , it can be seen that the wave power of the swells are greater than that of wind sea at all in-situ locations. Most of the time the highest wave power contributes to the wave comes from swell apart from wind sea.

During Phailin cyclone period, forecasted wave power was highest at BD08, (i.e., $174 \mathrm{~kW} / \mathrm{m}$ ) on 12th October, 2013. The interesting point noticed is that the highest wave power forecasted during Phailn was double than that of the Hudhud (figure 9b-j). Moreover, forecasted wave power has shown highest value $(148 \mathrm{~kW} / \mathrm{m})$ at Gopalpur which is 50 times greater than that of Visakhapatnam during Hudhud cyclone (figure $9 \mathrm{~g}-\mathrm{j}$ ). From figure 9 , it is observed that forecasted wave powers are higher during Phailin rather than Hudhud. The cyclone-generated wind sea and swell altogether contributed in forecasting the high wave powers.

\section{Conclusion}

The focus of this study was the validation of the ESSO-INCOIS wave forecast during two very severe cyclones, Phailin and Hudhud in the Bay of Bengal. The MIKE21 SW model simulated wave parameters are validated with in-situ and satellite observations. The validation is done separately for deep and shallow water regions. The bulk statistics computed during extreme events shows good agreement of wave forecast with the observations of in-situ and altimeter measurements. Further comparison of one dimensional spectra reveals the accurate simulation of wind seas and swells by SW model during extreme events. The study reveals that the ECMWF winds are good quality but the time lag associated in forcing the winds are responsible for the lag in forecasting peak values of the waves during landfall period. The wave power computed at moored and shallow water buoys shows more contribution of swell waves to wave power rather than wind seas. The coastal regions which lie on the right side of the VSCS tracks receive powerful waves during the whole period of the cyclones. Powerful wind seas $(>80 \mathrm{~kW} / \mathrm{m})$ are found during landfall time in the east coast of India. Present study shows that BoB has experienced severe high wave powers, twice that of Huhud, during Phailin cyclone. The evaluation of abnormality index shows under extreme events the coast of Gopalpur was severely affected by cyclonegenerated waves due to shoaling and refraction.

\section{Acknowledgements}

Authors wish to thank the Director, Indian National Centre for Ocean Information Services, Ministry of Earth Sciences, Govt. of India, Hyderabad, for motivation and encouragement. The in-situ data for the analysis was provided by National Institute of Ocean Technology, MoES, India. The authors wish to thank Delft Institute for Earth Oriented Space Research Radar Altimeter Data base system (http://rads.tudelft. $\mathrm{nl} / \mathrm{rads} /$ rads.shtml) for providing Radar Altimeter data. Thanks are also due to Mr. Kaviyazhahu, Mr. Arun N, Mr. Jeyakumar, Mr. Ramakrishna Phani of INCOIS for their valuable help. Finally, the financial help given by the Earth System Science Organisation, Ministry of Earth Sciences, Government of India, is gratefully acknowledged. This is INCOIS contribution no. 243.

\section{References}

Aboobacker V M, Vethamony P, Sudheesh K and Rupali S P 2009 Spectral characteristics of the nearshore waves off Paradip, India during monsoon and extreme events; J. Nat. Hazards 49 311-323.

Alam Md M, Hossain Md A and Shafee S 2003 Frequency of Bay of Bengal cyclonic storms and depressions crossing different coastal zones; Int. J. Climatol. 23 1119-1125.

Andersson 2013 User guide to ECMWF forecast products; Ver. 1.1, New terminology, ENS initial perturbations.

Balakrishnan Nair T M, Sirisha P, Sandhya K G, Srinivas K, Sanil Kumar V, Sabique L, Nherakkol Arun, Krishna Prasad B, Kumari Rakhi, Jeyakumar C, Kaviyazhahu K, Ramesh Kumar M, Harikumar R, Shenoi S S C and Nayak Shailesh 2013 Performance of the ocean state forecast system at Indian National Centre for Ocean Information Services; Curr. Sci. 105 175-181. 
Balakrishnan Nair T M, Remya P G, Harikumar R, Sandhya K G, Sirisha P, Srinivas K, Nagaraju C, Nherakkol Arun, Krishna Prasad B, Jeyakumar C, Kaviyazhahu K, Hithin N K, Kumari Rakhi, Sanil Kumar V, Ramesh Kumar M, Shenoi S S C and Nayak Shailesh 2014 Wave forecasting and monitoring during very severe cyclone Phailin in the Bay of Bengal; Curr. Sci. 106 1121-1125.

Cavaleri L 1994 Applications to wave hindcasting and forecasting (Chapter IV); In: Dynamics and Modelling of Ocean Waves, Cambridge University Press, UK, $532 \mathrm{p}$.

DHI Water and Environment 2014 MIKE 21 spectral wave module; Scientific documentation.

Dube S K, Rao A D, Sinha P C, Murty T S and Bahulayan N 1997 Storm surge in the Bay of Bengal and Arabian Sea: The problem and its prediction; J. Mausam 48 283-304.

Glejin Johnson, Sanil Kumar V, Balakrishnan Nair T M, Singh Jai and Nherakkol Arun 2014 Freak waves off Ratnagiri, west coast of India; Indian J. Mar. Sci. 43 1-7.

IMD Report 2013 Very Severe Cyclonic Storm, Phailin over the Bay of Bengal (8-14 October 2013): A Report; Cyclone Warning Division, India Meteorological Department, New Delhi.

IMD report 2014 Very Severe Cyclonic Storm, Hudhud over the Bay of Bengal (8-14 October 2013): A Report; Cyclone Warning Division, India Meteorological Department, New Delhi.

Mohanty U C, Krishna K, Osuri Routray A, Mohapatra M and Pattanayak Sujata 2010 Simulation of Bay of Bengal tropical cyclones with WRF model: Impact of initial and boundary conditions; J. Marine Geodesy 33 294-314.

Nayak S, Bhaskaran P K, Venkatesan R and Dasgupta S 2013 Modulation of local wind waves at Kalpakkam from remote forcing effects of southern ocean swells; J. Ocean Eng. 64 23-35.
Neumann C J 1993 Global overview; In: Global Guide to Tropical Cyclone Forecasting, World Meteorological Organization, Geneva; pp. 1.1-1.56.

Parise Claudia K and Farina Leandro 2014 Wave spectra generated by an extra tropical cyclone in south Atlantic Ocean; J. Tellus 1-10.

Peter D, Bromirski James and Kossin P 2008 Increasing hurricane wave power along the US Atlantic and Gulf coasts; J. Geophys. Res. 113 1-10.

Ponce de León and Guedes Soares 2014 Extreme wave parameters under north Atlantic extra tropical cyclones; J. Ocean Modelling 81 78-88.

Remya P G, Kumar Raj, Basu S and Sarkar A 2012 Wave hindcast experiments in the Indian Ocean using MIKE 21 SW model; J. Earth Syst. Sci. 121 385-392.

Sabique L, Annapurnaiah K, Balakrishnan Nair T M and Srinivas K 2012 Contribution of southern Indian Ocean swells on the wave heights in the northern Indian Ocean - A modeling study; J. Ocean Eng. 43 113-120.

Sandhya K G, Balakrishnan Nair T M, Bhaskaran P K, Sabique L, Arun N and Jeyakumar K 2014 Wave forecasting system for operational use and its validation at coastal Puducherry, east coast of India; J. Ocean Eng. 80 $64-72$.

Schrama E, Scharroo R and Naeije M 2000 Radar Altimeter Database System (RADS): Towards a generic multi-satellite altimeter database system; Final Report, SRON/BCRS publ., USP-2 report 00-11, $88 \mathrm{p}$.

Sorensen O R, Kofoed-Hansen H, Rugbjerg M and Sorensen L S 2004 A third-generation spectral wave model using an unstructured finite volume technique; Proc. Int. Conf. Coastal Eng. 29 894-906.

Subbaramayya I, Ramanadham R and Subba Rao 1979 The November 1977 Andhra Pradesh cyclone and the associated storm surge. 